\title{
Ocorrência de bactérias clinicamente relevantes nos resíduos de serviços de saúde em um aterro sanitário brasileiro e perfil de susceptibilidade a antimicrobianos
}

\author{
Occurrence of clinically relevant bacteria in health service waste in a \\ Brazilian sanitary landfill and antimicrobial susceptibility profile
}

\author{
Thiago César Nascimento ${ }^{1}$, Werlley de Almeida Januzzi ${ }^{1}$, Mariléia Leonel${ }^{2}$, \\ Vânia Lúcia da Silva ${ }^{1}$ e Cláudio Galuppo Diniz ${ }^{1}$
}

\begin{abstract}
RESUMO
Os resíduos de serviços de saúde suscitam polêmica quanto a importância para a saúde humana, animal e ambiental. Avaliou-se a ocorrência de bactérias clinicamente relevantes na pilha de resíduos de serviços de saúde em um aterro sanitário e seu perfil de susceptibilidade aos antimicrobianos. Alíquotas de chorume foram processadas para isolamento seletivo de Staphylococcus sp, bastonetes Gram negativos da família Enterobacteriaceae e não fermentadores. Resistência bacteriana a todos os antimicrobianos testados foi observada em todos os grupos microbianos, além de resistência a mais de uma droga. Os resultados permitem sugerir que bactérias viáveis nos resíduos de serviços de saúde representam riscos à saúde humana e animal. Além disso, a ocorrência de linhagens multirresistentes sustenta a hipótese dos resíduos de serviços de saúde atuarem como reservatórios de marcadores de resistência, com impacto ambiental. A falta de legislação regional de segregação, tratamento e destino de resíduos podem expor diferentes populações a riscos de transmissão de doenças infecciosas associadas a microrganismos multirresistentes.
\end{abstract}

Palavras-chaves: Resíduo de serviço de saúde. Staphylococcus sp. Enterobacteriaceae. Bastonetes Gram negativos não-fermentadores. Resistência antimicrobiana.

\begin{abstract}
Health service waste gives rise to controversy regarding its importance for human, animal and environmental health. Occurrences of clinically relevant bacteria in piles of health service waste in a sanitary landfill and their antimicrobial susceptibility profile were evaluated. Aliquots of leachate were processed for selective isolation of Staphylococcus sp, Gram-negative rods of the Enterobacteriaceae family and non-fermenters. Bacterial resistance to all the antimicrobials tested was observed in all microbial groups, including resistance to more than one drug. The results make it possible to suggest that viable bacteria in health service waste represent risks to human and animal health. Furthermore, occurrences of multiresistant strains support the hypothesis that health service waste acts as a reservoir for resistance markers, with an environmental impact. The lack of regional legislation concerning segregation, treatment and final disposal of waste may expose different populations to risks of transmission of infectious diseases associated with multiresistant microorganisms.
\end{abstract}

Key-words: Health service waste. Staphylococcus sp. Enterobacteriaceae. Non-fermenting Gram-negative rods. Antimicrobial resistance.

Entre os diferentes tipos de resíduos gerados pelo homem, os produzidos nos serviços de saúde têm merecido maior atenção nos últimos anos, principalmente devido às suas frações infectantes. Devido à grande variedade de fontes geradoras de resíduos, a

\footnotetext{
1. Laboratório de Fisiologia e Genética Molecular Bacteriana, Departamento de Parasitologia, Microbiologia e Imunologia, Instituto de Ciências Biológicas, Universidade Federal de Juiz de Fora, Juiz de Fora, MG. 2. Departamento de Enfermagem Materno-Infantil e Saúde Pública, Faculdade de Enfermagem, Universidade Federal de Juiz de Fora, Juiz de Fora, MG.

Apoio Financeiro: Fundação de Amparo à Pesquisa do Estado de Minas Gerais (FAPEMIG) Endereço para correspondência: Prof. Cláudio Galuppo Diniz. Laboratório de Fisiologia e Genética Molecular Bacteriana/Dept ${ }^{\circ}$ de Parasitologia, Microbiologia e Imunologia/ICB/UFJF, Campus Universitário s/nº, Martelos, 36036-900 Juiz de Fora, MG. Telefax: 5532 3229-3213

e-mail: claudio.diniz@uff.edu.br

Recebido para publicação em 25/03/2009

Aceito em 11/08/2009
}

legislação vigente classifica os mesmos segundo sua origem. Esta legislação, entretanto, é de competência regional, e variações na classificação dos resíduos podem existir. Como legislação federal norteadora, no Brasil, a Agência Nacional de Vigilância Sanitária (ANVISA) classifica os resíduos quanto a sua origem em: domiciliar, comercial, varrição e feiras livres, serviços de saúde, portos, aeroportos e terminais rodoviários e ferroviários, industriais, agrícolas e resíduos de construção civil ${ }^{12}$.

De maneira expressiva, no Brasil, mais de 30 mil unidades de saúde produzem resíduos de serviços de saúde (RSS), e, na maioria das cidades, a questão do manejo não está resolvida. Além disso, algumas unidades de saúde desconhecem a quantidade e a composição dos resíduos que produzem5.

É grande e polêmica a discussão sobre a importância e o significado dos RSS no potencial de risco para a saúde humana 
e ambiental. Vários autores afirmam que não existem fatos que comprovem que o resíduo hospitalar seja mais contaminado que 0 resíduo doméstico e que possa causar doença no ambiente hospitalar ou na comunidade ${ }^{1415}{ }^{19}$. As exceções unânimes são os resíduos perfurocortantes e as culturas microbiológicas. 0 risco de contaminação pelo manuseio desses resíduos é alto, tanto no momento da geração, do acondicionamento e do descarte, quanto durante a coleta externa e a disposição final, devido às suas características físicas e ao seu potencial de contaminação através de microrganismos retidos, requerendo normas seguras de manuseio e acondicionamento ${ }^{13}$.

Vários microrganismos podem ser encontrados nos RSS e, quando não são patógenos obrigatórios, apresentam grande potencial patogênico, considerando-se, sobretudo, a susceptibilidade dos possíveis hospedeiros (humanos ou não) que entrem, eventualmente, em contato com eles. Destacam-se bactérias da microbiota anfibiôntica, tais como: Enterococcus sp, Klebsiella sp, Salmonella sp, Shigella sp, Vibrio cholerae, Streptococcus pneumoniae; Staphylococcus spp e Staphylococcus aureus. Além destes, outros microrganismos como Neisseria gonorrhoeae; Bacillus anthracis; vírus do herpes; vírus da imunodeficiência humana; vírus das hepatites A, B e C; Candida albicans e outros fungos também podem ser encontrados. Há de se considerar, ainda, a ocorrência de helmintos e outros parasitas nos RSS ${ }^{2}$.

Desta forma, considerando a potencialidade dos RSS como agentes de disseminação de microrganismos potencialmente patogênicos para os seres humanos e outros animais, além de veículo para disseminação de marcadores de resistência a drogas antimicrobianas, avaliou-se a ocorrência de bactérias clinicamente relevantes nesses resíduos, como representantes da família Enterobacteriaceae, bastonetes Gram negativos não fermentadores (BGNNF), cocos Gram positivo do gênero Staphylococcus, e o seu perfil de susceptibilidade a drogas antimicrobianas de interesse clínico-microbiológico.

\section{MATERIAL E MÉTODOS}

Isolamento e identificação de amostras bacterianas nos resíduos do serviço de saúde. Alíquotas de $10 \mathrm{ml}$ de chorume percolado foram obtidas da pilha de resíduos do serviço de saúde, no aterro sanitário do Departamento Municipal de Limpeza Urbana (DEMLURB), entre novembro de 2006 e abril de 2007, em Juiz de Fora, MG. Os materiais foram imediatamente transportados ao Laboratório de Fisiologia e Genética Molecular Bacteriana do ICB/UFJF. Amostras bacterianas foram isoladas após cultura nos seguintes meios seletivos: ágar bile verde brilhante (Difco Laboratories, Detroit, MI), para isolamento de representantes da família Enterobacteriaceae e de BGNNF entéricos; e ágar hipertônico manitol (Difco Laboratories) para isolamento de linhagens representativas de Staphylococcus.

As amostras representativas isoladas da família Enterobacteriaceae e do grupo dos BGNNF foram identificadas presuntivamente por métodos bioquímico-fisiológicos convencionais, como já estabelecido para identificação destas espécies ${ }^{7}$. Os testes incluíram avaliação da morfologia celular pela coloração de Gram, fermentação dos carboidratos glicose, lactose e sacarose, produção de indol, fenilalanina, ureia, $\mathrm{H}_{2} \mathrm{~S}$, lisina e motilidade, citrato de Simmons, lisina descarboxilase e citocromooxidase. As linhagens de Staphylococcus foram identificadas presuntivamente pela habilidade de fermentação anaeróbica da glicose, produção das enzimas catalase e coagulase e teste da fermentação do manitol, de acordo com a literatura ${ }^{1011}$.

Avaliação do perfil de susceptibilidade a drogas antimicrobianas. A concentração inibitória mínima (CIM) foi determinada pelo método de diluição em ágar, segundo recomendações do Clinical Laboratory Standards Institute ${ }^{3}$. Concentrações crescentes (de $0,0625 \mu \mathrm{g} / \mathrm{ml}$ a $1.024,0 \mu \mathrm{g} / \mathrm{ml}$ ) das drogas, a partir de soluções estoque, foram adicionadas a frascos contendo meio ágar Mueller Hinton fundido (HiMedia Laboratories, Mumbai, Índia) e vertido em placas estéreis. As drogas antimicrobianas foram selecionadas com base em sua relevância clínica: ampicilina, gentamicina, cloranfenicol e a associação ampicilina/sulbactam (para Enterobacteriaceae), ceftazidima, ciprofloxacina, gentamicina e cloranfenicol (para BGNNF); rifamicina, penicilina, oxacilina, ciprofloxacina e eritromicina (para Staphylococcus). Linhagens de referência, cujos perfis de susceptibilidade aos antimicrobianos são conhecidos, foram incluídas, como controle de qualidade: Staphylococcus aureus 29213 e Escherichia coli ATCC 25922.

\section{RESULTADOS}

No período, foram coletadas sete amostras de chorume percolado da pilha de RSS no aterro sanitário de Juiz de Fora/ MG. Foram isoladas 73 amostras de Staphylococcus coagulase negativo, 72 amostras de bastonetes Gram negativos da família Enterobacteriaceae e 36 amostras bastonetes Gram negativos não fermentadores (BGNNF). Entre os Gram negativos da família Enterobacteriaceae, 58,3\% (42/72) foram presuntivamente identificados como Citrobacter sp; 8,3\% (6/72) como Providencia sp; 9,7\% (7/72) como Klebsiella sp; 8,3\% (6/72) como Proteus sp; 5,6\% (4/72) como Escherichia coli; 2,8\% (2/72) como Hafnia sp; 2,8\% (2/72) como Morganella sp Foram identificadas, também, uma amostra de Salmonella sp(1,4\%), uma Shigella sp (1,4\%) e uma Serratia sp (1,4\%). Entre os BGNNF, 61,1\% (22/36) foram identificados presuntivamente como Acinetobacter sp e 38,9\% (14/36) como Pseudomonas sp.

Os resultados dos testes de susceptibilidade aos antimicrobianos são mostrados na Tabela 1 e estão apresentados em termos de $\mathrm{CIM}_{50}$ (concentração inibitória mínima, na qual 50\% dos isolados testados foram inibidos) e CIM $_{90}$ (concentração inibitória mínima, na qual $90 \%$ dos isolados testados foram inibidos), além da variação das CIMs.

Considerando-se os Staphylococcus coagulase negativo, eritromicina foi a droga menos efetiva, com taxa de resistência de $57 \%$, seguida pela penicilina $(56 \%)$, oxacilina $(53 \%)$ e rifamicina (47\%). Ciprofloxacina foi o antimicrobiano mais efetivo, embora $25 \%$ das linhagens tenham apresentado resistência intermediária. Em relação aos bastonetes Gram negativos da 
família Enterobacteriaceae, a ampicilina foi o antimicrobiano menos efetivo, com taxa de resistência de 83\%, seguido da associação ampicilina-sulbactam (75,6\%), gentamicina (39\%) e cloranfenicol (36,6\%). Avaliando-se os BGNNF, cloranfenicol foi 0 antimicrobiano menos efetivo, com taxa de resistência de $88,9 \%$, seguido da ceftazidima $(61,1 \%)$. As menores taxas de resistência aos antimicrobianos foram observadas para as drogas gentamicina e ciprofloxacina $(22,2 \%)$.

A Tabela 2 mostra a distribuição dos padrões de susceptibilidade às drogas, considerando resistência a um ou mais agentes antimicrobianos. Entre as 68 linhagens de Staphylococcus, 12 (17,6\%) foram susceptíveis a todas as drogas

\section{TABELA 1}

Concentração inibitória mínima (CIM) de antimicrobianos para linhagens bacterianas representativas de Staphylococcus sp coagulase negativo, bastonetes Gram negativos (BGN) da família Enterobacteriaceae e BGN não fermentadores isolados de chorume produzido por resíduos de serviços de saúde do aterro sanitário da Cidade de Juiz de Fora, MG.

\begin{tabular}{|c|c|c|c|}
\hline \multirow[b]{2}{*}{ Número de linhagens representativas e antimicrobianos testados } & \multicolumn{3}{|c|}{ Concentração inibitória mínima $(\mu \mathrm{g} / \mathrm{ml})$} \\
\hline & $50 \%$ & $90 \%$ & variação \\
\hline \multicolumn{4}{|l|}{ Staphylococcus coagulase negativo $\left(\mathrm{n}^{0}=68\right)$} \\
\hline rifamicina & 0,5 & 16,0 & $0,06-16,0$ \\
\hline oxacilina & 2,0 & $>1.024,0$ & $0,06->1.024,0$ \\
\hline eritromicina & 32,0 & 64,0 & $0,06-512,0$ \\
\hline penicilina & 2,0 & $>1.024,0$ & $0,06->1.024,0$ \\
\hline ciprofloxacina & 0,25 & 2,0 & $0,06-2,0$ \\
\hline \multicolumn{4}{|l|}{ BGN família Enterobacteriaceae $\left(\mathrm{n}^{0}=41\right)$} \\
\hline ampicilina & 256,0 & $1.024,0$ & $0,25->1.024,0$ \\
\hline ampicilina/sulbactam & 64,0 & 256,0 & $0,12->1.024,0$ \\
\hline gentamicina & 8,0 & 64,0 & $0,25-256,0$ \\
\hline cloranfenicol & 16,0 & 64,0 & $8,0-128,0$ \\
\hline \multicolumn{4}{|l|}{ BGN não-fermentadores $\left(n^{0}=18\right)$} \\
\hline ceftazidima & 128,0 & $1.024,0$ & $2,0->1.024,0$ \\
\hline ciprofloxacina & 0,5 & 8,0 & $0,25-32,0$ \\
\hline gentamicina & 4,0 & 32,0 & $1,0-256,0$ \\
\hline cloranfenicol & 64,0 & 64,0 & $16,0-64,0$ \\
\hline
\end{tabular}

\section{TABELA 2}

Distribuição dos padrões de susceptibilidade a drogas, considerando resistência a um ou mais agentes antimicrobianos entre as amostras bacterianas representativas isoladas de chorume produzido por resíduos de serviços de saúde do aterro sanitário da Cidade de Juiz de Fora, MG.

\begin{tabular}{|c|c|c|c|c|}
\hline \multirow[t]{2}{*}{ Linhagens representativas $\left(\mathrm{n}^{\mathrm{o}}\right)$} & \multicolumn{3}{|c|}{ Fenótipo de resistência } & \multirow{2}{*}{$\begin{array}{l}\text { Susceptibilidade } \\
\text { a todas as drogas }\end{array}$} \\
\hline & Droga & $\mathrm{n}^{0}$ & $\%$ & \\
\hline \multirow[t]{6}{*}{ Staphylococcus sp coagulase negativo $\left(\mathrm{n}^{\mathrm{0}}=68\right)$} & ERY & 18 & 26,5 & $\mathrm{n}^{0}=12 ; 17,6 \%$ \\
\hline & PEN & 1 & 1,5 & \\
\hline & $\mathrm{ERY} / \mathrm{PEN}$ & 1 & 1,5 & \\
\hline & OXA/PEN & 2 & 2,9 & \\
\hline & ERY/RIF/OXA/PEN & 17 & 25,0 & \\
\hline & ERY/RIF/OXA/PEN/CIP & 17 & 25,0 & \\
\hline \multirow[t]{7}{*}{ BGN família Enterobacteriaceae $\left(\mathrm{n}^{0}=41\right)$} & AMP/GEN & 1 & 2,4 & $\mathrm{n}^{0}=4 ; 9,8 \%$ \\
\hline & $\mathrm{AMP} / \mathrm{CHL}$ & 1 & 2,4 & \\
\hline & AMP/AMS & 3 & 7,3 & \\
\hline & AMP/GEN/CHL & 2 & 4,9 & \\
\hline & AMP/AMS/CHL & 6 & 14,7 & \\
\hline & AMP/AMS/GEN & 3 & 7,3 & \\
\hline & AMP/AMS/GEN/CHL & 21 & 51,2 & \\
\hline \multirow[t]{6}{*}{ BGN não-fermentadores $\left(\mathrm{n}^{\circ}=18\right)$} & CHL & 4 & 22,2 & $\mathrm{n}^{0}=0 ; 0,0 \%$ \\
\hline & CHL/GEN & 1 & 5,6 & \\
\hline & $\mathrm{CHL} / \mathrm{CAZ}$ & 3 & 1,7 & \\
\hline & $\mathrm{CHL} / \mathrm{CAZ} / \mathrm{CIP}$ & 6 & 33,3 & \\
\hline & $\mathrm{CHL} / \mathrm{CAZ} / \mathrm{GEN}$ & 2 & 11,1 & \\
\hline & CHL/CAZ/GEN/CIP & 2 & 11,1 & \\
\hline
\end{tabular}

BGN: bastonete Gram negativos, ERY: eritromicina, PEN: penicilina, OXA: oxacilina, RIF: rifamicina, CIP: ciprofloxacina, AMP: ampicilina, GEN: gentamicina, CHL: cloranfenicol, AMS: ampicilina-sulbactam, CAZ: ceftazidima. 
testadas, enquanto 19 (28\%) foram resistentes a pelo menos uma droga testada. Resistência simultânea a dois antimicrobianos foi observada, sendo uma linhagem resistente à eritromicina/ penicilina e duas linhagens resistentes à oxacilina/penicilina; 17 linhagens foram resistentes a quatro drogas antimicrobianas (eritromicina/rifamicina/oxacilina/penicilina); e 17 linhagens foram resistentes a estas mesmas quatro drogas, além de apresentarem resistência intermediária à ciprofloxacina.

Entre as 41 linhagens de Enterobacteriaceae, quatro (9,8\%) foram sensíveis a todos os antimicrobianos, enquanto cinco linhagens apresentaram resistência simultânea a duas drogas (ampicilina/gentamicina, ampicilina/cloranfenicol ou ampicilina/ ampicilina-sulbactam); 11 linhagens apresentaram resistência a três drogas (ampicilina/gentamicina/cloranfenicol ou ampicilina/ gentamicina/ampicilina-sulbactam ou ainda ampicilina/ cloranfenicol/ampicilina-sulbactam); 21 linhagens apresentaram resistência simultânea a quatro drogas (ampicilina/gentamicina/ cloranfenicol/ampicilina-sulbactam).

Considerando os BGNNF, quatro (22,2\%) linhagens apresentaram resistência a no mínimo uma droga testada; quatro linhagens apresentaram resistência simultânea a duas drogas (cloranfenicol/gentamicina ou cloranfenicol/ceftazidima); oito linhagens apresentaram resistência a três drogas (cloranfenicol/ ceftazidima/ciprofloxacina ou cloranfenicol/ceftazidima/ gentamicina); e duas linhagens apresentaram resistência a quatro drogas (cloranfenicol/ceftazidima/ciprofloxacina/gentamicina).

\section{DISCUSSÃO}

A avaliação microbiológica do chorume produzido a partir da pilha de resíduos do serviço de saúde no Aterro Sanitário da Cidade de Juiz de Fora/MG mostrou que estes resíduos, quando descartados sem tratamento prévio, permitem a manutenção de diferentes espécies bacterianas viáveis com percentuais elevados de linhagens resistentes a diferentes drogas antimicrobianas de uso clínico tanto hospitalar quanto comunitário.

A resistência aos antimicrobianos é um fenômeno genético, relacionado à existência de genes contidos nos microrganismos, que codificam diferentes mecanismos bioquímicos e que impedem a ação das drogas ${ }^{18}{ }^{20}$. A contenção deste fenômeno em nosso meio figura como um dos grandes desafios da ciência no século XXI, e vários são os apelos dos órgãos de saúde internacionais, que preconizam estudos regionais sobre a crescente resistência bacteriana, o desenvolvimento de agentes antimicrobianos, os efeitos da resistência aos antimicrobianos nas doenças infecciosas e a determinação das possíveis rotas de disseminação de marcadores de resistência das bactérias ${ }^{18}$.

Neste estudo, observou-se a ocorrência de linhagens bacterianas de grande relevância clínica, tais como Staphylococcus coagulase negativo, bastonetes Gram negativos não-fermentadores e espécies da família Enterobacteriaceae, resistentes a importantes drogas betalactâmicas, como a penicilina e a ampicilina. Pela análise do perfil de susceptibilidade aos betalactâmicos associados a inibidores de betalactamases, observa-se que a maioria das linhagens resistentes aos primeiros provavelmente é produtora de betalactamases, o que representa um grande problema na nossa realidade hoje. Além disso, a resistência simultânea de algumas linhagens aos betalactâmicos associados a inibidores de betalactamases permite sugerir que haja resistência por outros mecanismos ${ }^{6}$. Observou-se também resistência às cefalosporinas, como a ceftazidima, em linhagens de bastonetes Gram negativos não-fermentadores.

Além disso, observou-se um importante índice de resistência a drogas importantes contra Staphylococcus coagulase negativo, como a oxacilina. A ocorrência destas linhagens no nosso meio é importante, não apenas pelo indicativo de resistência cruzada, como também de disseminação de marcadores de resistência ${ }^{3}$.

No Brasil, a disposição final da maior parte dos RSS é inapropriada. A política de segregação municipal destes resíduos baseia-se, sobretudo, no seu descarte em lixões, embora uma pequena parcela receba tratamento adequado e destino final em aterro sanitário ${ }^{1617}$. Os impactos provocados pelos resíduos sólidos municipais podem estender-se para a população em geral, direta ou indiretamente, por meio da poluição e contaminação dos corpos hídricos e dos lençóis subterrâneos, dependendo do uso da água e da absorção de material tóxico ou contaminado 9 .

Nossos resultados, ainda que preliminares, reforçam as reflexões relacionadas ao papel destes resíduos como reservatórios de patógenos microbianos putativos, além de linhagens resistentes aos antimicrobianos. Embora acredite-se que outros tipos de resíduos associados às atividades humanas possam representar riscos também potenciais, nossos resultados permitem sugerir que a carga de antimicrobianos usada nos serviços de saúde possa contribuir para a seleção de marcadores de resistência com grande impacto, neste caso, para os diferentes ecossistemas. Além disso, a falta de legislação regional cientificamente fundamentada de segregação, tratamento e destino de resíduos pode expor profissionais e indivíduos das comunidades de áreas de aterros a riscos de transmissão de doenças infecciosas associadas a bactérias multirresistentes.

\section{AGRADECIMENTOS}

Os autores são gratos ao Departamento Municipal de Limpeza Urbana do município de Juiz de Fora e ao Programa de PósGraduação em Saúde (Saúde Brasileira) da Universidade Federal de Juiz de Fora.

\section{REFERÊNCIAS}

1. American Society for Microbiology. Antimicrobial Resistance an Ecological Perspective. Report From the American Academy of Microbiology. American Society for Microbiology, Washington, DC, 2000.

2. Bidone FRA. Resíduos sólidos provenientes de coletas especiais: eliminação e valorização. Abes, Rio de Janeiro, 2001.

3. Clinical and Laboratory Standards Institute. Performance Standards for Antimicrobial Susceptibility Testing. In: Abstract of the $15^{\text {th }}$ Informational Supplement. Clinical and Laboratory Standards Institute document. M100-S17 (ISBN 1-56238-625-5), Wayne, Pennsylvania, USA, 2007.

4. Deus ABS, De Luca SJ, Clarke RT. Índice de impacto dos resíduos sólidos urbanos na saúde pública (IIRSP): metodologia e aplicação. Revista Engenharia Sanitária e Ambiental 9: 329-334, 2004. 
5. Ferreira JA. Resíduos sólidos e lixo hospitalar: uma discussão ética. Cadernos de Saúde Pública 11: 314-320, 1995.

6. Fisher JF, Meroueh SO, Mobashery S. Bacterial resistance to beta-lactam antibiotics: compelling opportunism, compelling opportunity. Chemical Reviews 105:395-424, 2005.

7. Koneman EW, Allen SD, Janda WM, Schreckenberger PC, Winn WC. Diagnóstico Microbiológico. Texto e Atlas Colorido. $6^{\text {a }}$ edição, Guanabara Koogan, Rio de Janeiro, 2008.

8. Levy SB. The challenge of antibiotic resistance. Scientific American 278: 32-39, 1998.

9. Machado C, Prata $\mathrm{F}^{\circ} \mathrm{DA}$. Gestão de Resíduos Sólidos Urbanos em Niterói. In: Anais do $20^{\circ}$ Congresso Brasileiro de Engenharia Sanitária e Ambiental, Rio de Janeiro, Cd-rom. III,1999.

10. Madigan MT, Martinko JM, Parker J. Microbiologia de BROCK. $10^{a}$ edição. Pretince Hall, São Paulo, 2004.

11. Mc Faddin JF. Biochemical tests for identification of medical bacteria. Williams \& Wilkins Company, Baltimore, 1977.

12. Ministério da Saúde. Manual de gerenciamento de resíduos de serviços de saúde. Série A - Normas e Manuais Técnicos. Agência Nacional de Vigilância Sanitária, Brasília, 2006.

13. Nazar MW, Pordeus IA, Werneck MAF. Dental waste management in municipal health clinics in Belo Horizonte, Brazil. Revista Panameriacana de Salud Publica 17: 237-242, 2005.
14. Rutala WA, Odette RL, Samsa GP. Manegement of infectious waste by us hospitals. The Journal of the American Medical Association 262: 1635-1640, 1989.

15. Rutala WA, Sarubbi Jr FA. Management of waste from hospitals. Infection Control 4: 198-204, 1983.

16. Segura-Munoz SIS. Impacto ambiental na área do aterro sanitário e incinerador de resíduos sólidos de Ribeirão Preto, SP: Avaliação dos níveis de metais pesado. Tese de Doutorado, Escola de Enfermagem de Ribeirão Preto - EERP, Universidade de São Paulo, Ribeirão Preto, SP, 2002.

17. Souza EL. Medidas para prevenção e minimização da contaminação humana e ambiental causadas pelos resíduos de serviços de saúde gerados em estabelecimento hospitalar - estudo de caso. Tese de Doutorado, Centro de Recursos Hídricos e Ecologia Aplicada - CRHEA, Universidade de São Paulo, São Paulo, SP, 2005.

18. Tavares W. Bactérias Gram-positivas problemas: resistência do estafilococo, do enterococo e do pneumococo aos antimicrobianos. Revista da Sociedade Brasileira de Medicina Tropical 33: 281-301, 2000.

19. Zanon U. Riscos infecciosos imputados ao lixo hospitalar: realidade epidemiológica ou ficção sanitária? Revista da Sociedade Brasileira de Medicina Tropical 23: 163-170, 1990.

20. Zavadinack M, Herreiro F, Bandeira COP, Ito Y, Ciorlin E, Saqueti EE, Ansileiro IJ, Gonçalves L, Siqueira VLD. Staphylococcus aureus: incidência e resistência antimicrobiana em abscessos cutâneos de origem comunitária. Acta Scientiarum 23: 709-712, 2001. 